\title{
A switchable reagent ion high resolution time-of-flight chemical ionization mass spectrometer for real-time measurement of gas phase oxidized species: characterization from the 2013 southern oxidant and aerosol study
}

\author{
P. Brophy and D. K. Farmer \\ Department of Chemistry, College of Natural Sciences, Colorado State University, 1872 Campus Delivery, Fort Collins, \\ CO 80523, USA
}

Correspondence to: D. K. Farmer (delphine.farmer@colostate.edu)

Received: 23 February 2015 - Published in Atmos. Meas. Tech. Discuss.: 20 March 2015

Revised: 24 June 2015 - Accepted: 29 June 2015 - Published: 22 July 2015

\begin{abstract}
A novel configuration of the Aerodyne high resolution time-of-flight chemical ionization mass spectrometer (HR-TOF-CIMS) as a switchable reagent ion (SRI) HRTOF-CIMS is presented and described along with data collected at the Southern Oxidant and Aerosol Study (SOAS) during the summer of 2013. The calibration system and reduced pressure gas phase inlet are characterized. The average limit of detection and limit of quantification for formic acid during SOAS are 82 and 863 ppt, respectively, corresponding to an average sensitivity of $13 \pm 5 \mathrm{~Hz} \mathrm{ppt}^{-1}$. Hourly background determinations and calibrations are shown to be essential for tracking instrument performance and accurately quantifying formic acid. Maximum daytime formic acid concentrations of $10 \mathrm{ppb}$ are reported during SOAS, and a strong diel cycle is observed leading to nighttime concentrations below the limit of quantification. Other species presented exhibit diel behavior similar to formic acid. The concept of the mass defect enhancement plot and the use of signal-tonoise are described in detail as a method for investigating HR-TOF-CIMS spectra in an effort to reduce data complexity.
\end{abstract}

\section{Introduction}

Chemical ionization mass spectrometry (CIMS) remains an active area of research and development despite its long history of atmospheric application. CIMS instrumentation con- tinues to increase the number and diversity of quantifiable compounds in both the gas and aerosol phase due, primarily, to advances in mass spectrometry. The choice of reagent ion is paramount to detecting atmospherically relevant compounds with a high degree of sensitivity without interference from other species (Huey, 2007). The concept of CIMS relies on selectively ionizing a subset of the molecular species present in the sampled air in order to simplify analysis and reduce isobaric interferences. This is the key to quadrupole based mass spectrometers, which do not provide sub-unit mass resolution and can suffer from isobaric interferences when analyzing complex mixtures without separation. High resolution time-of-flight chemical ionization mass spectrometers (HR-TOF-CIMS) capable of determining molecular composition help to alleviate this problem with species differing slightly in exact mass, but they cannot directly distinguish between conformational isomers (Nozière et al., 2015). As such, reagent ion selectivity remains the key to unambiguously analyzing atmospheric samples by CIMS regardless of the detector resolution. Conversely, reagent ion selectivity also limits the amount of information one can obtain from an atmospheric sample. Multiple reagent analysis maintains the benefit of selectivity while increasing the number of detectible species.

The use of multiple reagent ions provides a wealth of information and allows investigators to observe the system of interest using different ionization schemes; each reagent ion softly, little to no fragmentation of neutral species upon ionization, ionizes different species to a different degree provid- 
ing the analyst with different sets of detectible species. The proton-transfer-reaction mass spectrometry (PTR-MS) community implements this approach to a limited extent through the use of hollow cathode technology to produce not only $\mathrm{H}_{3} \mathrm{O}^{+}$but also $\mathrm{NO}^{+}$and $\mathrm{O}_{2}^{+}$(Jordan et al., 2009). $\mathrm{NO}^{+}$is known to be a soft ionizer like $\mathrm{H}_{3} \mathrm{O}^{+}$, and $\mathrm{O}_{2}^{+}$is less soft and can provide another option for ionizing species of interest. Selected ion flow tube mass spectrometry (SIFT-MS) using $\mathrm{H}_{3} \mathrm{O}^{+}, \mathrm{NO}^{+}$, and $\mathrm{O}_{2}^{+}$reagents is well studied, and rapidly switching the reagent ion and simultaneous use of two reagent ions at once are reported with promising results (Smith and Španěl, 2005). The major limitation noted in these studies is peak overlap on a quadrupole based mass spectrometer. Laboratory examples using multiple reagent analysis are limited. Investigations of the aqueous phase photooxidation of levoglucosan (Zhao et al., 2014) and the ozonolysis of $\alpha$-pinene (Aljawhary et al., 2013) use multiple reagent ions (iodide, protonated water clusters, and acetate) in their analysis. These different ionization schemes provide very different mass spectra and a more comprehensive picture of the underlying chemistry. The fact that few studies use multiple reagent analysis is not surprising. Recent commercialization of the field-deployable HR-TOF-CIMS has started to transition the CIMS field from thinking about individual compounds, primarily due to hardware limitations of quadrupole based systems, to ensembles of compounds detected across a large mass range (Chhabra et al., 2015).

Typical CIMS measurements utilize one reagent ion throughout a measurement campaign or various regent ions in controlled laboratory settings where experiments can be repeated; the latter case provides a broader suite of compounds than the use of a single reagent ion. Reagent ions are generated from two component gas mixtures (usually nitrogen and a precursor reagent molecule) and exposed to either a radioactive source (Po-210 or Am-241) or a hollow cathode source. The reagent ion flow mixes with ambient sample and selectively ionizes neutral species. Matrix effects can alter ionization efficiency in different ways for different reagent ions. For example, iodide ionization of organic acids exhibits a strong dependence on relative humidity but not necessarily the same dependence for every analyte (Kercher et al., 2009; Mielke et al., 2011; Lee et al., 2014; Woodward-Massey et al., 2014). High backgrounds are also a problem for CIMS measurements. Wentzell et al. (2014) report high formic acid backgrounds using the acetate reagent ion preventing the measurement of formic acid during chamber studies. This highlights two problems with CIMS measurements: the preparation of clean air without detectible concentrations of species of interest for reproducible background measurements, and the production of reagent ion gas mixtures without numerous side products that contribute to instrument background. Both issues affect instrument backgrounds and can increase the limit of detection.
Five reagent ions outside the PTR-MS and SIFT-MS field have seen recent application to ambient atmospheric measurements: protonated water clusters $\left(\mathrm{H}_{2} \mathrm{O}\right)_{n} \mathrm{H}^{+}$, iodide water clusters $\mathrm{I}\left(\mathrm{H}_{2} \mathrm{O}\right)_{n}^{-}$, nitrate $\mathrm{NO}_{3}^{-}, \mathrm{CF}_{3} \mathrm{O}^{-}$, and acetate $\mathrm{CH}_{3} \mathrm{CO}_{2}^{-}$. These reagents and the relevant literature are summarized by Aljawhary et al. (2013). Effectively implementing a reagent ion scheme involves tuning the mass spectrometer voltages to optimize the detection of the product ions or clusters. For example, the acetate ion requires strong declustering electric fields such that all detectable species (M) are observed as deprotonated ions (Reaction R1a) and not as clusters (Reaction R1b) (Chhabra et al., 2015).

$\mathrm{H}-\mathrm{M}+\mathrm{CH}_{3} \mathrm{C}(\mathrm{O}) \mathrm{O}^{-} \rightarrow \mathrm{CH}_{3} \mathrm{C}(\mathrm{O}) \mathrm{OH}+\mathrm{M}^{-}$
$\mathrm{H}-\mathrm{M}+\mathrm{CH}_{3} \mathrm{C}(\mathrm{O}) \mathrm{O}^{-} \rightarrow\left[\mathrm{CH}_{3} \mathrm{C}(\mathrm{O}) \mathrm{O}^{-} \cdot \mathrm{M}-\mathrm{H}\right]$.

Alternatively, the use of iodide water clusters requires the opposite treatment of the electric fields. Species detected by iodide appear primarily as clusters (Reaction R2), and their efficient transfer to the time-of-flight region of the instrument is crucial to maintain high sensitivity (Lee et al., 2014).

$\mathrm{I}-\mathrm{H}_{2} \mathrm{O}^{-}+\mathrm{M} \rightarrow \mathrm{I}-\mathrm{M}^{-}+\mathrm{H}_{2} \mathrm{O}$

In modern instrumentation, voltages associated with the mass spectrometer's transfer optics to increase or decrease clustering can be modified rapidly $(<1 \mathrm{~s})$. Changing the polarity of the instrument to detect negative and positive ions is relatively slow ( $>1 \mathrm{~min}$ ). The ion molecule reactor and radioactive source used for water cluster, iodide, $\mathrm{CF}_{3} \mathrm{O}^{-}$, and acetate CIMS is the same, but nitrate systems have substantially different reactors. Water cluster CIMS operates in positive mode, while the others operate in negative mode. The storage and preparation of $\mathrm{CF}_{3} \mathrm{O}^{-}$remains challenging compared to the other methods (Crounse et al., 2006). For these reasons, this paper proposes online switching between iodide and acetate CIMS, with the added benefit that acetate's sensitivity to acids is independent of water vapor (Veres et al., 2008). Here, we describe the switchable reagent ion (SRI) HR-TOF-CIMS, characterize its background, sensitivity and stability, and use ambient measurements taken during the Southern Oxidant and Aerosol Study to describe a method for examining the bulk high resolution data.

\section{Site description}

The Southern Oxidant and Aerosol Study (SOAS) set out to understand the interactions of biogenic and anthropogenic emissions in the southeastern United States. The SOAS ground supersite, located in Brent, Alabama (32.903016 $-87.250104^{\circ}$ ) included gas, aerosol, and meteorological instruments. The site is located in a cleared field on top of a hill surrounded by dense hardwood and pine forests in a rural landscape. High temperature $\left(24.7^{\circ} \mathrm{C}\right.$ average, $32.7^{\circ} \mathrm{C}$ max, $\left.17.4^{\circ} \mathrm{C} \mathrm{min}\right)$ and high relative humidity $(81.8 \% \mathrm{RH}$ average, 
$100 \% \mathrm{RH} \max , 37.9 \% \mathrm{RH} \min )$ characterize the summer months. The SRI-HR-TOF-CIMS was housed in an air conditioned trailer located on top of the cleared hill. The instrument inlet was positioned above the trailer roof at a height of $6 \mathrm{~m}$ with a total length of approximately $7.5 \mathrm{~m}$.

\section{Instrument description}

We demonstrate online reagent ion switching for gas phase field measurements during the SOAS campaign in an effort to measure a broader suite of compounds and utilize the advantages associated with a high resolution time-of-flight mass spectrometer.

\subsection{The HR-TOF-CIMS}

The HR-TOF-CIMS (Tofwerk AG and Aerodyne Research, Inc.) (Figs. 1, S1 in the Supplement) is described extensively in the literature (DeCarlo et al., 2006; Bertram et al., 2011; Yatavelli et al., 2012; Lee et al., 2014), and we offer a brief description here. The HR-TOF-CIMS can sample at or below atmospheric pressure using an atmospheric pressure interface (APi) that reduces the pressure through a series of four sequential pressure drops leading to the high vacuum time-offlight chamber (Junninen et al., 2010). In a chemical ionization (CI) configuration, ambient air enters the ion molecule reactor (IMR) and mixes with the CI reagent ion. IMR pressure is independently controlled by a single scroll SH-110 pump (Agilent Technologies). Ions generated in the IMR pass through two sets of segmented, RF-only quadrupoles and a lens stack prior to entering the orthogonal extraction region of the time-of-flight mass spectrometer.

The first segmented quadrupole is the short segmented quadrupole (SSQ) located after the IMR in a separate vacuum region held at 2 mbar by a Triscroll 600 pump (Agilent Technologies). The segmented quadrupole provides a linear voltage drop across the length of the quadrupole, and it helps to control both the transmission of ion-neutral clusters through the APi and contributes to the mass-tocharge $(\mathrm{m} / \mathrm{z})$ dependent transmission efficiency of the instrument. Subsequent vacuum regions housing the second set of segmented quadrupoles, lens stack, and time-of-flight chamber are pumped by a split-flow turbomolecular pump (Pfeiffer Vacuum Technology AG) backed by an MD-1 diaphragm pump (Vaccubrand, Inc.). The second, larger set of segmented, RF-only quadrupoles (the "big segmented quadrupole", BSQ) has similar functionality as the SSQ. Lastly, the lens stack helps to align the ion trajectory into the orthogonal extraction region, affecting the resolution $(m / \Delta m)$ and the shape of the observed high resolution peak.

Ion counts detected on the micro channel plate detector (Photonis Inc) are amplified and pre-averaged on the analog to digital converter (ADQ1600, SP Devices) before being sent to the computer (Dell Power Edge R220) via a

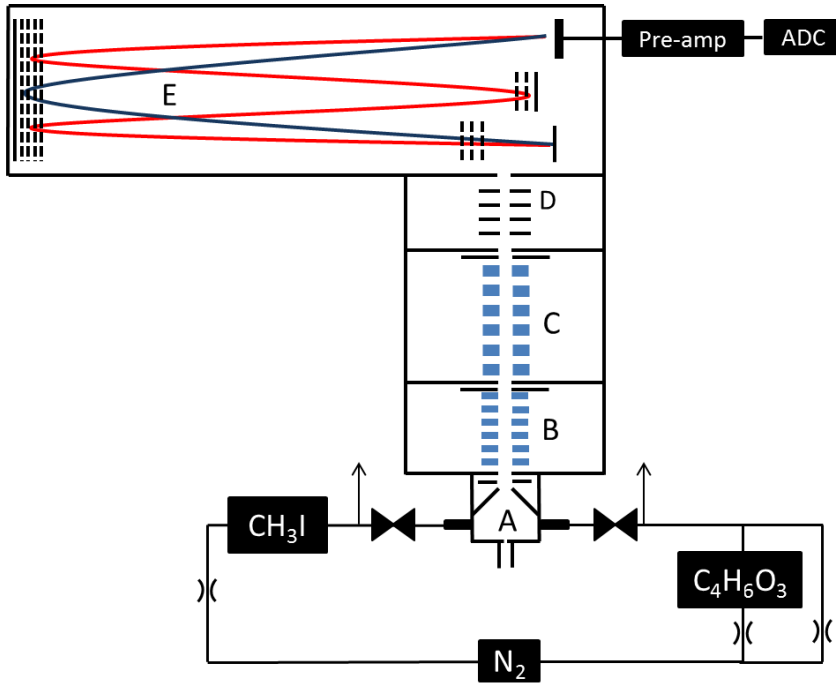

Figure 1. Schematic of the SRI-HR-TOF-CIMS including the different regions of the atmospheric pressure interface. Reagent ions enter the IMR (A) and mix with incoming ambient air. The first RF-only short segmented quadrupole (SSQ, B) guides ions through the second reduced pressure region into the third stage housing the second RF-only big segmented quadrupole (BSQ, C). Ions pass through a lens stack (D) prior to being orthogonally extracted into the time-of-flight chamber (E).

high speed USB connection. Online mass calibration occurs simultaneously with the data acquisition but requires additional post-processing. The instrument regularly achieves high mass accuracy $(<20 \mathrm{ppm})$ with mass resolution $>4000$. Mass spectra are acquired at an extraction frequency of $17 \mathrm{kHz}$ corresponding to a mass-to-charge $(\mathrm{m} / \mathrm{z})$ range of $15-1026$ in the negative mode at $1 \mathrm{~s}$ resolution.

\subsection{Ion generation}

Iodide and acetate reagent ions are chosen for this experiment for a variety of reasons.

1. Both ions are acquired in the negative mode, making APi voltage switching fast.

2. Acetate and iodide are commonly used in ambient field measurements.

3. The two reagent ions provide different sets of measureable compounds.

4. Iodide has humidity dependence, but acetate does not.

5. The methods of generating iodide and acetate ions are simple.

Acetate (also referred to as negative-ion proton-transfer CIMS (NI-PT-CIMS) or acid-CIMS) provides a method for softly ionizing gas phase organic and inorganic acids (Veres 
et al., 2008, 2011; Roberts et al., 2010; Yatavelli et al., 2012) and nitrated phenols (Mohr et al., 2013) with a high degree of sensitivity. Iodide measures oxidation products from isoprene and terpene species, acids, and various inorganic species (Huey et al., 1995; Slusher et al., 2004; Kercher et al., 2009; Aljawhary et al., 2013; Lee et al., 2014; WoodwardMassey et al., 2014). Together, the two CI methods provide measurements of gas phase species that are generally more oxidized than those observed using PTR-TOF-MS, but neither acetate nor iodide appear to provide measurements of extremely low volatility organic compounds (ELVOCs) that are observed using nitrate CI (Aljawhary et al., 2013; Ehn et al., 2014). $\mathrm{CF}_{3} \mathrm{O}^{-}$provides another interesting reagent ion choice that could be implemented on this system, but the difficulties associated with producing and storing the precursor pose a significant challenge compared to the facile methods of producing iodide and acetate reagent ions (Crounse et al., 2006).

Iodide ion generation on this instrument is similar to methods described in the literature (Slusher et al., 2004; Lee et al., 2014). Briefly, a home built methyl iodide (Sigma Aldrich, $99 \%$ Reagent Plus) permeation device constructed from $1 / 4^{\prime \prime}$ perfluoroalkoxy (PFA) tubing is placed inside a glass tube surrounded by a temperature controlled aluminum block held at $40^{\circ} \mathrm{C}$. Ultra high purity (UHP) nitrogen is flown over the permeation device at a rate of 2 standard liters per min (standard $\mathrm{L} \mathrm{min}{ }^{-1}$ ). Acetate ions are generated following the design presented by Veres et al. (2008). A 0.5 L electropolished stainless steel cylinder (Swagelok) filled with $300 \mathrm{~mL}$ of acetic anhydride (Sigma Aldrich, $\geq 99 \%$ Reagent Plus) is placed inside an aluminum block and heated to $50{ }^{\circ} \mathrm{C}$. UHP nitrogen delivered to the headspace of the cylinder at a rate of 5 standard cubic centimeters per minute $(\mathrm{sccm})$ mixes with the diluting flow to provide a total flow of approximately 2 standard $\mathrm{L} \mathrm{min}^{-1}$.

Both sources are switched on and off by activating an inline stainless steel solenoid valve (Parker Hannifin Corp, model 009-0272-900) using home built circuitry and a CoolCube (Parker Hannifin Corp) to prevent the valves from overheating during prolonged operation. Each source uses only stainless steel tubing and separate Po-210 ionizers (NRD, 10 $\mathrm{mCi}$ ) to reduce contamination between sources. The output of the ion sources ( 1 standard $\mathrm{L} \mathrm{min}^{-1}$ ) mixes with incoming ambient air $\left(2\right.$ standard $\left.\mathrm{L} \mathrm{min}^{-1}\right)$ in the IMR. The IMR is held at $60^{\circ} \mathrm{C}$ and $100 \mathrm{mbar}$ for the duration of the study.

\subsection{Source switching}

Switching the reagent ion mode requires changing the mass spectrometer voltages associated with the ion transfer optics in the APi in order to change the extent to which clustering occurs. A custom LabVIEW (National Instruments, LabVIEW 2013) interface is implemented using Tofwerk's Application Programing Interface (Tofwerk AG, Version 1.94) to control the instrument's data acquisition system, set volt- ages associated with the ion transfer optics, and synchronize all online automation. External devices and data streams are acquired using Labjack data acquisition devices (Labjack, model U12). Iodide voltage set points are optimized by maximizing the $\left[\mathrm{I} \cdot \mathrm{H}_{2} \mathrm{O}\right]^{-}$cluster relative to $\mathrm{I}^{-}$in an attempt to efficiently transfer iodide adducts to the ToF analyzer (Lee et al., 2014). Acetate voltage set points were optimized by minimizing the acetate acetic acid cluster, $[\mathrm{Ac} \cdot \mathrm{AcH}]^{-}$, relative to the acetate ion. The ratio between the acetate-acetic acid cluster and acetate is 0.02 , which is similar to the values reported by Mohr et al. (2013), using the Aerodyne HRTOF-CIMS. This value greatly differs from the value $(0.2)$ reported by Chhabra et al. (2015) using the same instrument. Careful tuning to minimize the $[\mathrm{Ac} \cdot \mathrm{AcH}]^{-}$is likely important for maintaining sensitivity, minimizing clustering with the acetate reagent ion via reaction $\mathrm{R} 1 \mathrm{~b}$, and avoiding mass spectral misinterpretation (Chhabra et al., 2015).

The LabVIEW program begins by switching the necessary valves to introduce and interrupt the appropriate reagent ion flows, and sends the associated voltage set points to the mass spectrometer's power supply and control hardware. Next, data acquisition is triggered from within the LabVIEW program starting the TOF extraction pulses and triggering the acquisition of data. Instrument acquisition parameters such as run time, $m / z$ range, and pre-averaging are preset. Once data acquisition is initiated from LabVIEW, the TOF data acquisition recorder runs until the acquisition runtime is met. LabVIEW and the associated Tofwerk Application Programing Interface monitor whether acquisition is active, and at the end of the run the program restarts by selecting the appropriate reagent configuration. Calibrations and external device control are typically initiated at the beginning of acquisition, but this is user selectable and customizable.

\subsection{Data analysis and high resolution processing}

Data are analyzed with Tofware (Aerodyne Research, Inc. and Tofwerk AG) and Igor Pro (Wavemetrics). The different reagent ion chemistries necessitate different data treatment in order to properly determine single ion peak shape, the masses used to determine instrument resolution, and ions suitable for mass calibration. Iodide mass calibration is conducted on $\mathrm{O}_{2}^{-}, \mathrm{Cl}^{-}, \mathrm{NO}_{2}^{-}, \mathrm{I}^{-}, \mathrm{IH}_{2} \mathrm{O}^{-}, \mathrm{IHNO}_{3}^{-}$, and $\mathrm{I}_{3}^{-}$. Acetate mass calibration is conducted on $\mathrm{O}_{2}^{-}, \mathrm{Cl}^{-}, \mathrm{NO}_{2}^{-}, \mathrm{C}_{2} \mathrm{H}_{3} \mathrm{O}_{2}^{-}, \mathrm{NO}_{3}^{-}$, $\mathrm{C}_{2} \mathrm{~F}_{3} \mathrm{O}_{2}^{-}$, and $\mathrm{C}_{4} \mathrm{H}_{7} \mathrm{O}_{4}^{-}$. In both cases, these ions provide a stable mass calibration over time. Both mass calibrations use a three parameter fit $\left(a \cdot m^{c}+b\right)$ included as an option within Tofware (DeCarlo et al., 2006). Baseline calculations use a pre-averaging algorithm for both iodide and acetate, which captures the baseline properly for most ions of interest. A TOF duty cycle correction is applied to the largest reagent ion signal, acetate or iodide, which corrects for the inherent mass-to-charge bias introduced from orthogonal extraction. High resolution (HR) analysis requires two separate lists of ion molecular formula for fitting, which differ signif- 


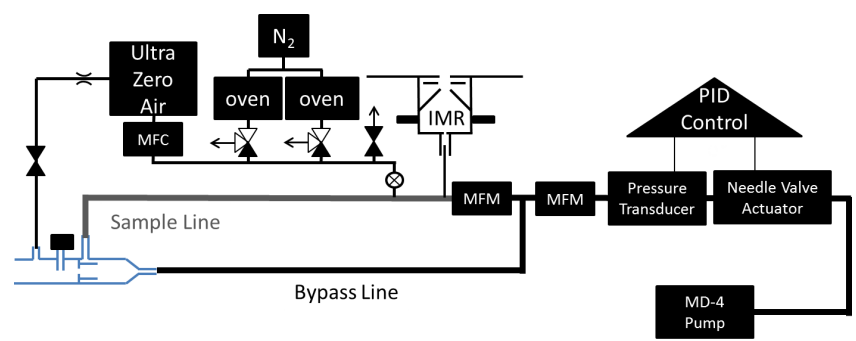

Figure 2. Schematic of the sampling and calibration setup during SOAS. The reduced pressure inlet and associated controls include two mass flow meters (MFM), a pressure transducer, needle valve actuator, pump, and computer PID controls. Valves show flow direction during ambient sampling.

icantly between ion sources. The SOAS data set undergoes pre-averaging from the original $1 \mathrm{~Hz}$ data to $0.1 \mathrm{~Hz}$ to expedite HR fitting calculations. After processing the HR ion fits, the data are normalized to the reagent ion signal $\left(\mathrm{I}^{-}\right.$and $\mathrm{CH}_{3} \mathrm{COO}^{-}$). The HR fit of iodide and acetate are used to normalize all ions detected with iodide and acetate, respectively. The subsequent treatment of the processed HR normalized data is completed using code written specifically for the analysis of the SOAS field campaign given the timing of hourly, automated calibrations and zeros.

\subsection{Fast flow, reduced pressure inlet with integrated atmospheric pressure calibration source}

A fast flow, reduced pressure borosilicate glass inlet with particle skimming geometry based on the work of Ellis et al. (2010) is used for SOAS measurements (Figs. 2, S2). Limited examples of particle skimming inlets exist in the literature but characterization remains lacking (Kercher et al., 2009).

\subsubsection{Reduced pressure inlet}

Significant modifications to the original design make the inlet suitable for interfacing to a mass spectrometer designed for trace gas detection. Ambient air (including both gases and particles) enter a $1^{\prime \prime} \mathrm{OD}$, thick walled glass tube at atmospheric pressure before passing through a $1.0 \mathrm{~mm}$ glass critical orifice. This orifice limits the flow to the pump and reduces the pressure of the inlet system. A large bypass flow pumps the inlet in line with the air passing through the critical orifice, and the sampling flow pulls air orthogonally to the flow crossing the critical orifice in an attempt to eliminate particles from contacting the IMR and sampling lines. The bypass line and sampling line reconnect after the IMR interface. Flow is monitored just after the IMR and after the two lines reconnect by means of two analog mass flow meters (MKS Instruments), thus providing a measure of total flow to the pump. Pressure monitoring with a Baratron (MKS Instruments, model 750C) occurs after both flow meters, and

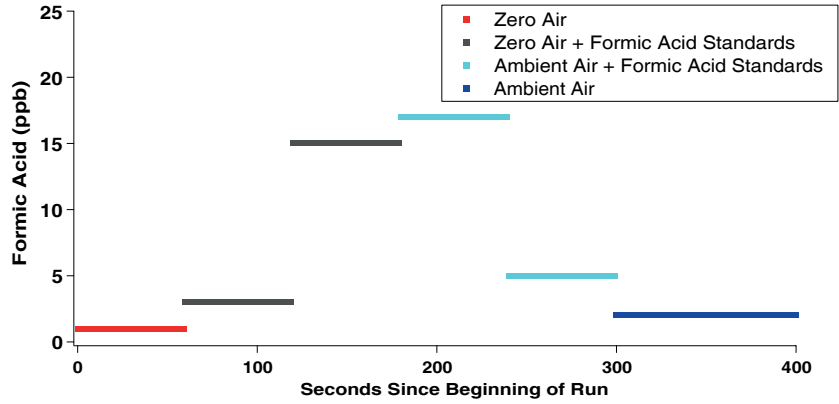

Figure 3. The calibration regimen was conducted hourly during SOAS, and allowed for calibration of formic acid in both dry ultrazero air (total hydrocarbon content $<0.01 \mathrm{ppm}$ ) and ambient air.

pressure is controlled using a fast-acting bidirectional electronic needle valve (Aalborg Instruments and Controls, Inc, model SMV20) and a proportional integral derivative loop (PID) run at $10 \mathrm{~Hz}$ from within the Labview software.

Pressure control is crucial for this inlet system because of the observed instability of the diaphragm pump (Vaccubrand Inc., model MD-4) and the use of a critical orifice to separate the IMR from the reduced pressure system. If pressure changes in the sampling line, then the sample flow to the IMR will change, and thus, the ratio of the reagent flow to the sample flow becomes unstable, complicating quantification. Two other major modifications from the original design include a lack of heating on the glass inlet to minimize shifts in gasparticle partitioning, and an increase in the total flow through the system.

\subsubsection{Integration of atmospheric pressure calibration source}

We integrate a permeation based calibration system into the low pressure inlet system for online calibrations with both zero air and ambient air. Calibrations conducted in zero air are external standard calibrations, and calibrations conducted in ambient air are standard addition calibrations. Instrument zeros and calibrations are conducted hourly at the beginning of each acquisition period (Fig. 3). The inlet design includes a port for zero air overflows and an additional port for inlet calibrations. The ultra-zero air overflow is controlled using a high pressure, normally closed solenoid valve (NResearch, Inc., model HP648T012) and a critical orifice (O'Keefe Controls, Inc., $C_{v}=0.031$ ) to provide a $>20$ standard $\mathrm{L} \mathrm{min}^{-1}$ overflow at the glass inlet. All gas lines leading from the high purity stainless steel regulator (Matheson TRIGAS Corp.) are $1 / 8^{\prime \prime}$ OD instrument grade stainless steel (Restek Corp.).

The calibration port is not used for this study due to the difficulty associated with transporting sticky calibration gases from permeation ovens (VICI Metronics, Dynacalibrator model 150) through long lengths of tubing to the glass inlet. Iodide and acetate reagent ions are sensitive to the fluori- 


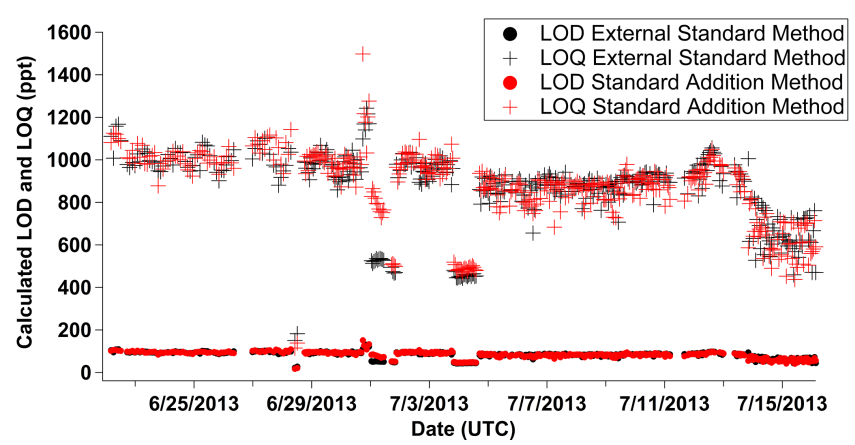

Figure 4. Time series of calculated limit of detection (LOD, circles) and limit of quantification (LOQ, crosses) for formic acid during hourly external standard (black) and standard addition (red) calibrations at SOAS while operating the instrument in acetate mode. The consistency between standard addition and external standard calibration demonstrates the lack of matrix effects from variation in relative humidity or other interferences.

nated compounds that outgas from PFA and FEP tubing, and these fluorinated compounds are known interferences for nitrate CIMS (Ehn et al., 2012). Attempts to use the calibration port in the field with long PFA transfer lines from the permeation oven to the inlet lead to the complete titration of the acetate reagent ion by fluorinated acidic compounds (trifluoroacetic acid and related compounds) outgassing from the tubing. Titration of the reagent ion makes calibration impossible. Instead, we introduce calibration gases into the reduced pressure inlet by interfacing a normally closed solenoid shutoff valve on the vent (NResearch Inc.), three way valves onto each permeation oven, and a PFA flow restricting needle valve (Swagelok, P/N: PFA-4RPS4) between the low pressure inlet line near the IMR entrance and the atmospheric pressure permeation source (Fig. 2). This setup allows calibration gas to flow into the low pressure inlet at controlled rates over a large range $\left(\sim 1\right.$ to $\left.1 \mathrm{~mL} \mathrm{~min}^{-1}\right)$ when the system is activated. The flow over the permeation device(s) is never interrupted and excess flow is vented during calibrations. An additional, controllable dilution of the permeation tube output by mass flow controller (MKS Instruments) can occur prior to introducing the flow to the low pressure inlet providing a method for producing a multipoint calibration curve over a very large calibration range. Complete formic acid calibration curves $(1-10 \mathrm{ppb})$ were conducted offline each day during the campaign as both external standard and standard addition calibrations.

\section{Results}

\subsection{Instrument performance}

The SRI-HR-TOF-CIMS SOAS data set includes 6 days of data with the instrument operating in switching mode and 18 days operating in acetate mode only. Switching occurs

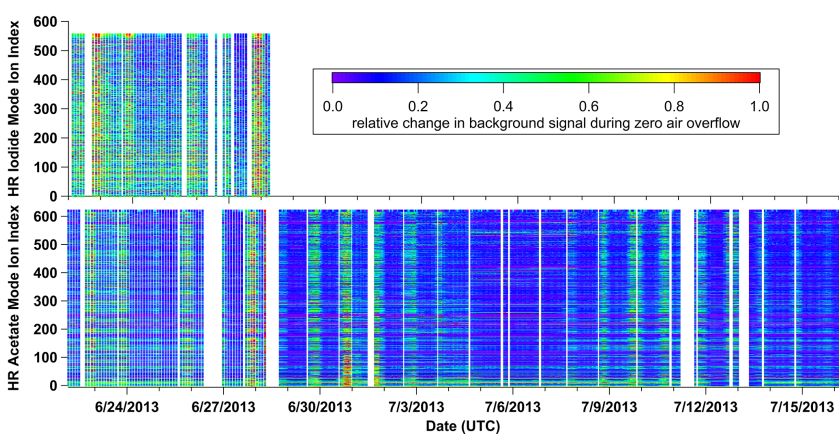

Figure 5. The relative change in the hourly background for every high resolution ion fit in both iodide mode and acetate mode demonstrates substantial differences in backgrounds for different ions, and the high degree of variability in backgrounds throughout the field deployment.

hourly between acetate and iodide. The inlet system maintains a constant 350 mbar sampling pressure (Fig. S3) and calibration system provides stable calibration and zero air for the entire measurement period. The instrument, however, exhibits variable sensitivity to the zeros and calibrations over the entire measurement period regardless of mode of operation. The hourly background measurements of formic acid using acetate vary by a relative standard deviation (RSD) of $153 \%$, and the standard addition calibrations and the external standard calibrations vary by a relative standard deviation of 50 and $41 \%$, respectively over the entire campaign. The limit of detection (LOD) and limit of quantification (LOQ) take into account both background count rate and sensitivity providing a better metric for evaluating instrument performance than sensitivity alone. The LOD and LOQ for formic acid during the entire measurement period using acetate vary by only $20 \%$ RSD. The average LOD and LOQ are 82 and $863 \mathrm{ppt}$, respectively, corresponding to an average sensitivity of $13 \pm 5 \mathrm{~Hz} \mathrm{ppt}^{-1}$. This sensitivity is consistent with other reported sensitivities to formic acid when adjusted for extraction frequency (Chhabra et al., 2015; Mohr et al., 2013; Yatavelli et al., 2012). A time series of the LOD and LOQ calculated each hour in acetate mode is provided (Fig. 4).Variability in formic acid background, sensitivity, and calculated limits of detection and quantification decrease when operating in switching mode compared to operation in dedicated acetate mode but likely reflects the length of time each mode operated during the campaign. The observed background variation during acetate mode is not limited to formic acid. Figure 5 shows the relative change in background counts for every HR ion fit plotted over the course of the entire SOAS campaign.

Background variation for iodide mode shows similar variability, and while representative of general instrument stability, these backgrounds do not capture the true background due to the use of dry zero air (Lee et al., 2014). During switching mode the iodide background for formic acid varies 


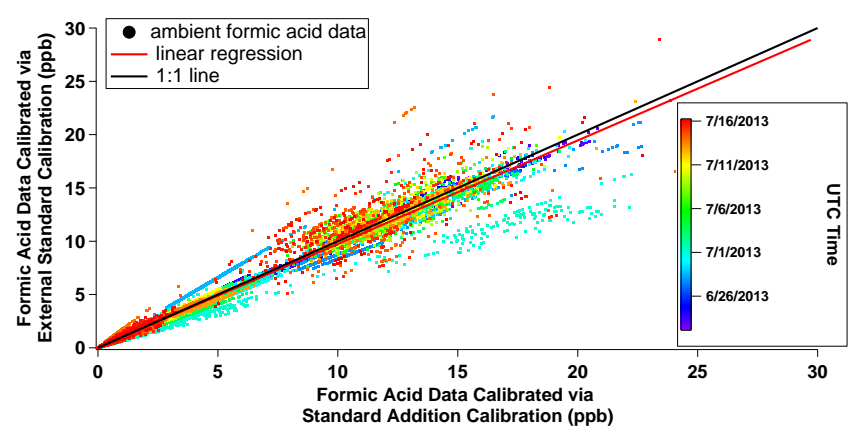

Figure 6. Scatterplot comparison of formic acid calibrated by standard addition and external standard during acetate mode.

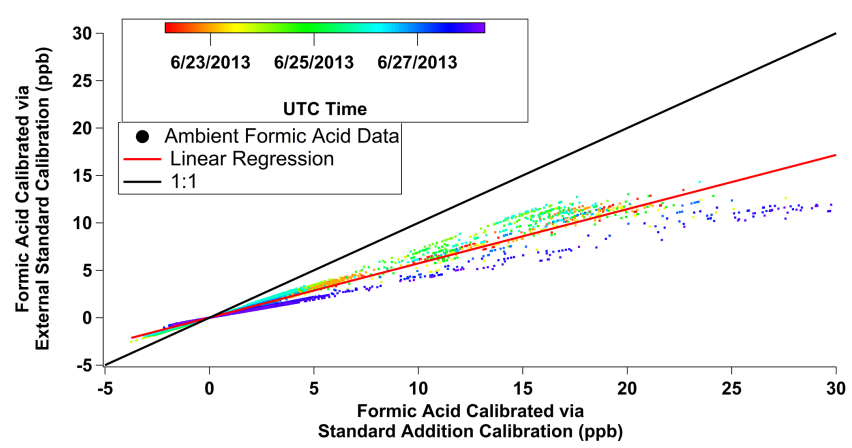

Figure 7. Scatterplot comparison of formic acid calibrated by standard addition and external standard during iodide mode. Linear regression of the data gives a slope of 0.57 , consistent with the humidity dependence of iodide ionization causing underestimation of formic acid when calibrated in dry air.

by $49 \%$ RSD, and acetate mode varies by $27 \%$ RSD. Higher variability is also observed for formic acid calibrations using iodide (20\% RSD) compared to acetate (5\% RSD). Variability in the background across the mass spectra is also observed for iodide as seen with acetate (Fig. 5).

Ambient data during acetate mode calibrated using the standard addition method and the external standard method are tightly correlated $\left(r^{2}=0.986\right)$ with a slope of $0.97 \mathrm{ex}-$ hibiting a nearly $1: 1$ relation (Fig. 6). The correlation between the two methods for calibration using iodide disagrees by a factor of 1.75 , likely due to the issues associated with humidity and ionization efficiency (Fig. 7).

\subsection{Quantified ambient formic acid data using the acetate reagent ion}

Three distinct time periods are observed in the formic acid time series (Fig. 8). The first and last time periods from 22 June to 3 July and from 8 to 16 July, respectively, exhibit strong diel trends. The ambient temperatures from 4 to 7 July were lower and coincident with daily rainfall, leading to lower gas phase concentrations often below the limit of quantification. The maximum observed formic acid concen-

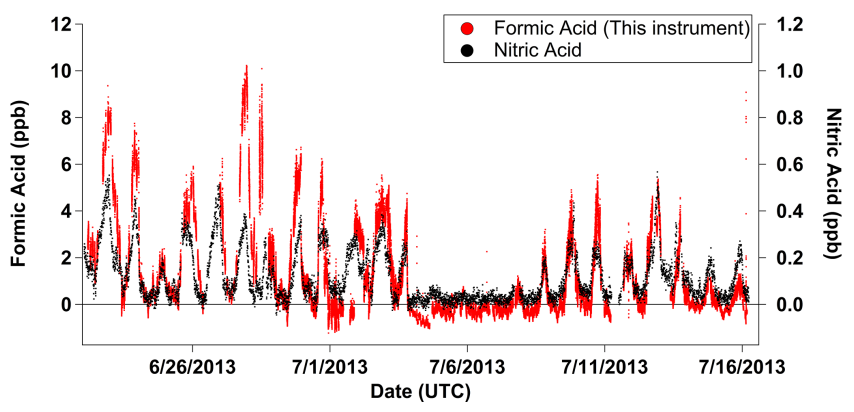

Figure 8. Formic acid time series (this instrument) showing a strong diel cycle from day to night. The behavior is strikingly similar to nitric acid, which is produced through secondary photochemistry and lost through rapid dry deposition. Nighttime formic acid concentrations consistently decrease below the limit of quantification, with daytime maximums in the $2-10 \mathrm{ppb}$ range, consistent with fast photochemical production and rapid sinks.

tration of $10 \mathrm{ppb}$ occurred on 27 June in the early evening ( $\sim 18: 00$, local time). The maximum daily formic acid concentrations from 22 June to 3 July and from 8 to 16 July both occur at approximately 18:00 local time. At night, concentrations consistently drop below the limit of quantification. Three other sets of acids are provided to show the temporal behavior of various acids, but calibrations are not currently available (Fig. 9a-c).

\subsection{Mass defect enhancement plots}

Numerous other acids present in the ambient acetate data show similar temporal behavior as formic acid with subtle differences depending on the species (Fig. 9a-c), but the number of species detected exceeds what is reasonable to publish as time series. Aljawhary et al. (2013) use a similar method where direct subtraction of mass defect plots is applied and referred to as the "difference mass defect plot." Figure 10a shows a mass defect plot of a normalized and background corrected $1 \mathrm{~h}$ average on the afternoon of 27 June 2013 between 15:00 and 16:00 local time of all the ions detected with acetate and assigned a HR ion fit. Figure $10 \mathrm{~b}$ shows the effect of filtering the data by signal-tonoise ratio and shows only the species with $\mathrm{S} / \mathrm{N}>3$. The mass defect $\left(d_{\mathrm{m}}\right)$ is the difference between the nominal mass and the exact mass of the detected ion. The mass defect of detected species plotted against the mass-to-charge ratio provides one space to examine complex, high resolution timeof-flight mass spectral data. The signal-to-noise ratio is defined as the ratio of one ion signal during ambient sampling divided by the standard deviation of that ion at some confidence level (typically $3 \sigma$ ) measured in zero air. Normally, signal-to-noise would be reported at some specific concentration, but calibration factors are not available for the majority of the species measured; this use of signal-to-noise criteria helps to filter out background ions and detected species that 


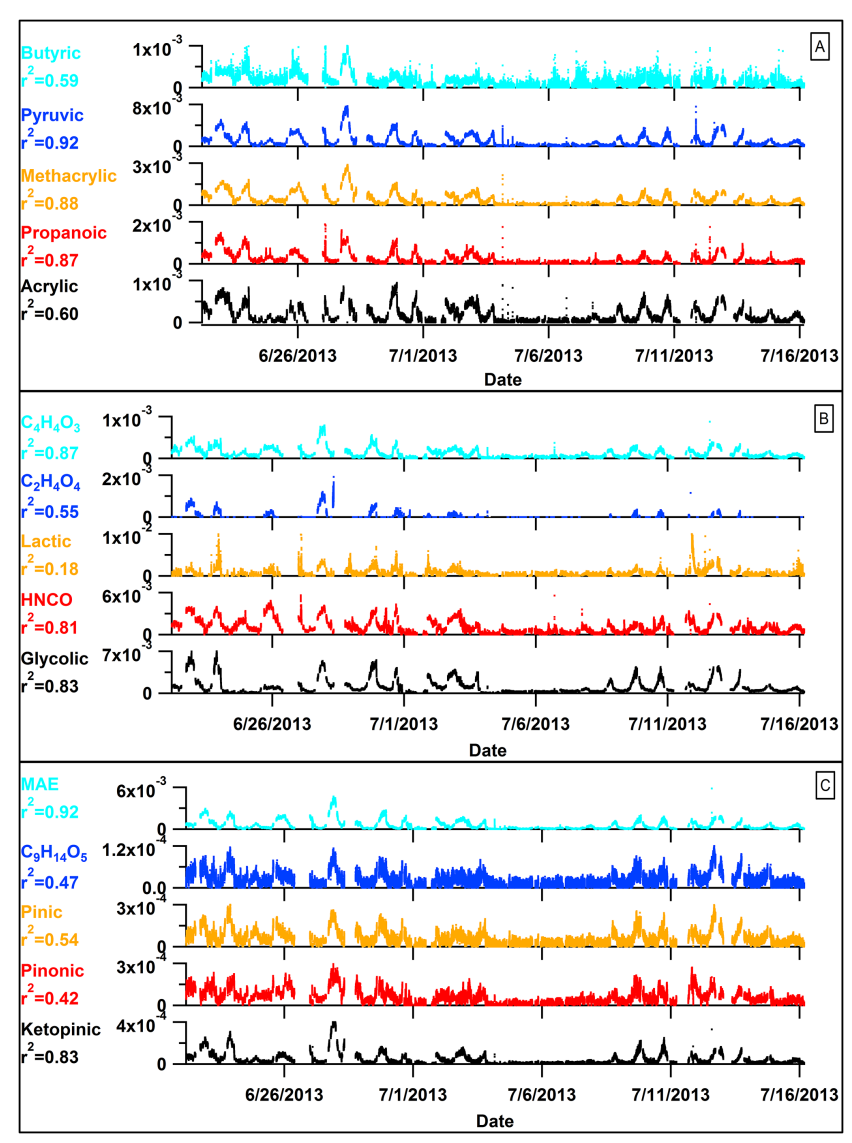

Figure 9. Time series of other acids observed with acetate ionization during SOAS. These compounds were not directly calibrated during the deployment, so signals are presented as counts per second normalized by the total reagent ion signal (acetate), and the correlation coefficient with formic acid is provided. (a) Acids commonly measured using acetate. (b) Species of interest. (c) Biogenic oxidation products with carboxylic acid functionality.

if we knew the calibration factor would still be below the statistically significant limit of detection. Of the 621 ions fit in the HR spectra, 423 are eliminated by imposing the signalto-noise cutoff.

CIMS measurements are characterized by high background signal, and we note that frequent online zeros are essential for examining data in this space due to background measurement instability. These frequent zeros can either directly provide an enhancement ratio or help to provide trustworthy enhancement ratios by constraining background variability. The enhancement ratio is defined as the ambient signal of the ion subtracted by the background signal and divided by the ambient signal expressed as a percent. Alternatively, if strong diel behavior is observed or if plumes are intercepted at an instrument's inlet, an enhancement ratio can be defined by a time of high or low signal acting as ambient or background signal, respectively. This type of analysis may be broadly useful for measurement techniques like
HR-TOF-CIMS that have high background signal as it clarifies which signals are truly present in ambient data. This approach is of particular interest for chamber studies where hundreds, or even thousands, of compounds are detected but many remain unchanged over the course of the experiment. Figure 10c shows the effect of applying the enhancement ratio cut off to eliminate species that change less than $5 \%$ from background using the same signal-to-noise filtered data as in Fig. 10b; this additional filtering eliminates 94 ions from the 198 ions meeting the signal-to-noise criteria. The diel method is also presented; Fig. 10d shows the mass defect enhancement plot of background subtracted data where the average signal during the photochemical minimum, occurring between 01:55 and 02:45 on 27 June, is used as the background and the photochemical maximum, occurring between 17:05 and 17:55 on 27 June, is used as the signal. Thus, the diel approach to mass defect plots quantifies the enhancement in signal in daytime over nighttime. One must recognize that this approach neglects species that do not change over time, but these may be of importance..

Representative time series are presented for iodide mode highlighting isoprene-related oxidation species detected as clusters with iodide (Fig. 11). Signal-to-noise criteria do not help to filter iodide data due to overall higher signal-to-noise ratios compared to acetate mode data. As such, a mass defect plot showing the species that change by more than $5 \%$ from 6:00 on 22 June to 18:00 on 22 June 2013 is presented and colored by the calculated percent change (Fig. 12). Out of $556 \mathrm{HR}$ ion fits between 32 and $328 \mathrm{~m} / z, 162$ ions change by less than $5 \%$.

Lastly, additional dimensions of data can aid in the interpretation of these enhancement mass defect plots. For example, one can perform cross correlation calculations on the ions of interest and color the enhancement mass defect plot by the correlation coefficient ( $r$ ) (Fig. S4). The correlation coefficient can be calculated for any species of interest against all other species or even calculated using auxiliary instrument data (wind direction, $\left[\mathrm{O}_{3}\right]$, ambient temperature, etc.) against all ions present on the enhancement mass defect plot. HR-TOF mass spectrometers have the added advantage of providing elemental composition. This can provide another descriptive parameter for exploring the enhancement mass defect plot; the oxygen to carbon ratio of ions with $\mathrm{S} / \mathrm{N}$ ratio $>3$ are presented in the Supplement (Fig. S5).

\subsection{Mass defect enhancement plots to evaluate inlet performance}

The mass defect enhancement plot is used to examine data collected during the characterization of the low pressure inlet system deployed during SOAS. A nitrogen gas overflow of the inlet under normal operating conditions is used to determine the time constant associated with detected species meeting the criteria of having a signal-to-noise ratio $>3$ and decreasing by at least $5 \%$. Molecular oxygen acts as a 


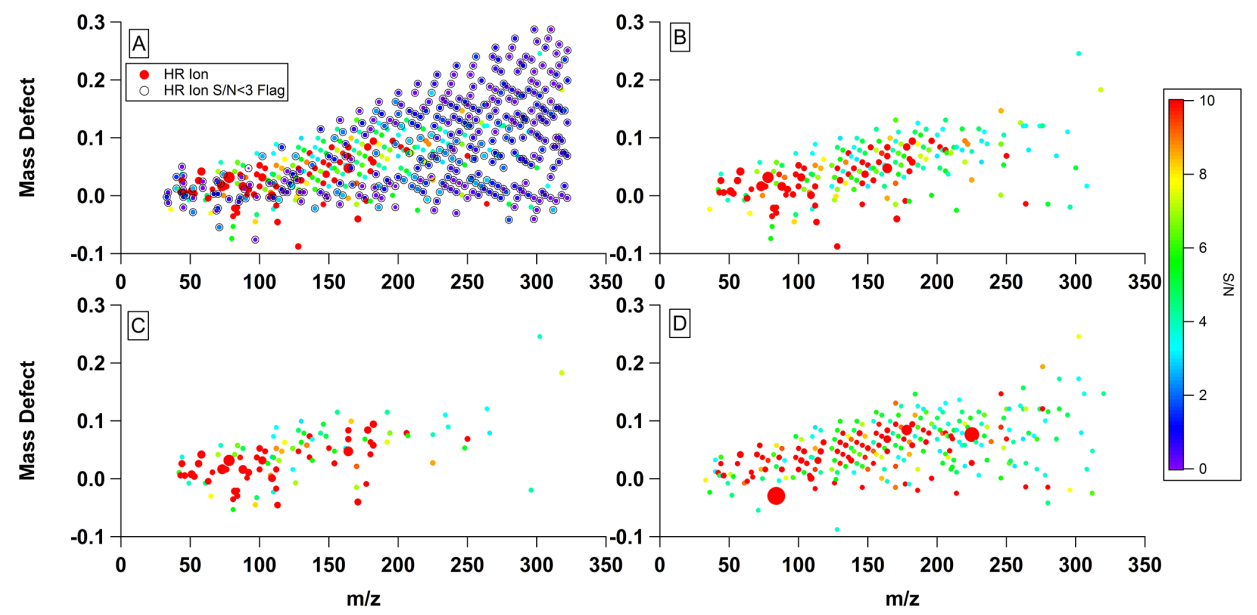

Figure 10. Mass defect enhancement plots showing the HR ion fits in acetate mode. (a-c) utilize the zero air method for defining background and signal between 15:00 and 16:00 local time on 27 June 2013. (a) All HR ion fits colored by S / N with ions having a S / N < 3 flagged. (b) HR ion fits with S / N > 3 only. (c) HR ion fits with S / N $>3$ and change by at least $5 \%$ compared to the zero. (d) utilizes the diel method for defining background (average mass spectrum during nighttime minimum) and signal (average mass spectrum during photochemical peak) and is also colored by the $\mathrm{S} / \mathrm{N}$ ratio. These data are also filtered by $\mathrm{S} / \mathrm{N}>3$ and change by $5 \%$.

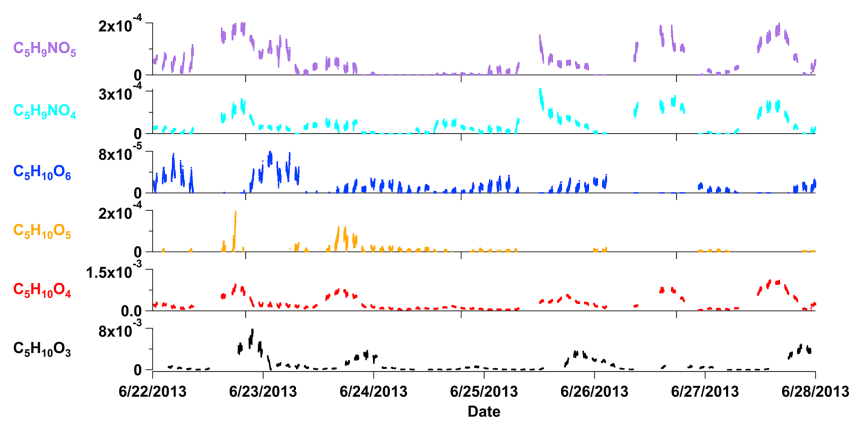

Figure 11. Select iodide species without direct calibration exhibit trends occurring on different timescales. Signals are in counts per second normalized by total reagent ion $\left(\mathrm{I}^{-}\right)$.

marker for the non-sticky component of ambient air sampled through the inlet. An offset exponential regression is performed on the time series of all species meeting the criteria during the nitrogen overflow to determine the time constant, $\tau$. This experiment was performed during the last night of SOAS at 22:45 local time on 15 July. Of the 621 ions fit in the HR spectra only 43 species meet the criteria and are plotted as a mass defect plot. The data are sized by signalto-noise ratio and colored by the time constant derived from regression (Fig. 13). Oxygen has a time constant of $1.2 \mathrm{~s}$ in the system.

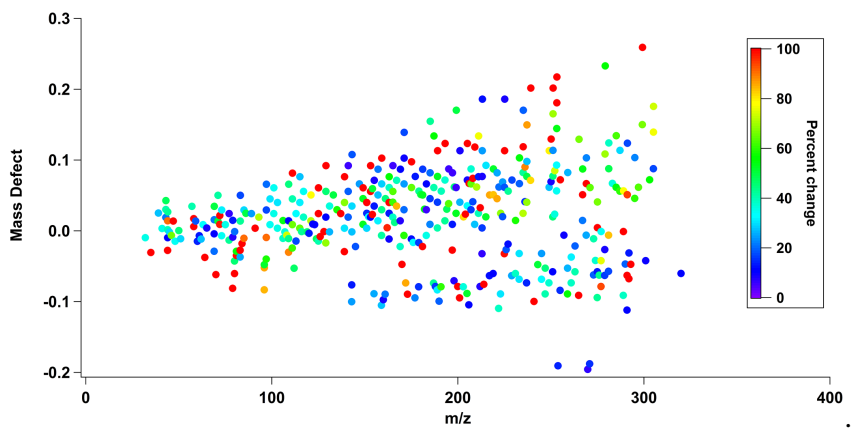

Figure 12. Mass defect plot of the iodide spectra colored by percent change from 6:00 on 22 June to 18:00 on 22 June 2013 and showing only species that change by $>5 \%$

\section{Discussion}

\subsection{Rapid reagent switching performance}

Switching quickly between acetate and iodide reagent sources every $10 \mathrm{~min}$ shows minimal reagent ion hysteresis (Fig. 14a). The primary source of the equilibration behavior observed immediately after switching sources is the time associated with pressure stabilization and the stabilization of the RF fields across the quadrupoles. Laboratory studies show that pressure stabilization takes $40 \mathrm{~s}$ after switching either source and corresponds to a pressure change of $10 \mathrm{mbar}$. SSQ and BSQ RF stabilization takes significantly longer $(\sim 2 \mathrm{~min})$ and is indirectly observed by examining the cluster distribution of acetate+acetic acid cluster $[\mathrm{Ac} \cdot \mathrm{AcH}]^{-}$and iodide+ + water cluster $\left[\mathrm{I} \cdot \mathrm{H}_{2} \mathrm{O}\right]^{-}$. 


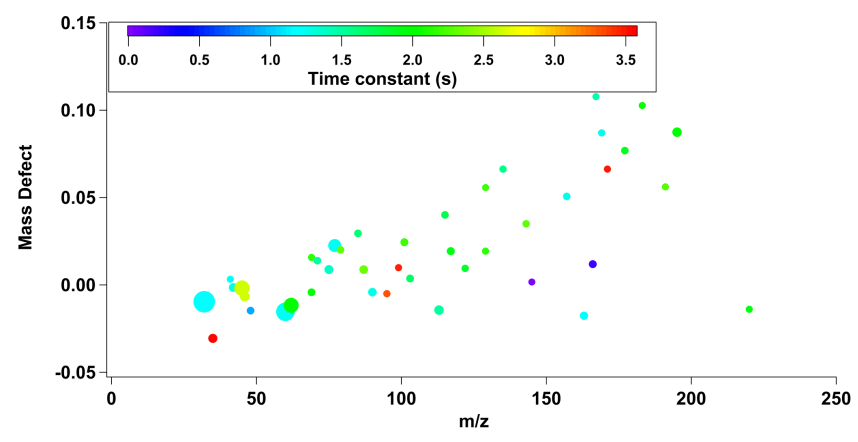

Figure 13. Mass defect enhancement plot for inlet characterization. Only ions with $\mathrm{S} / \mathrm{N}>3$ that decrease by at least $5 \%$ when overflowing the inlet with nitrogen are displayed. Points are colored by the time constant obtained from exponential fit analysis. The three ions with the longest residence times include $\mathrm{C}_{8} \mathrm{H}_{11} \mathrm{O}_{4}^{-}(3.48 \mathrm{~s})$, $\mathrm{C}_{4} \mathrm{H}_{3} \mathrm{O}_{3}^{-}$(3.43 s), and $\mathrm{Cl}^{-}(3.58 \mathrm{~s})$.

The ratio of the primary reagent ions for each mode, iodide and acetate, to the $\left[\mathrm{I} \cdot \mathrm{H}_{2} \mathrm{O}\right]^{-}$and $[\mathrm{Ac} \cdot \mathrm{AcH}]^{-}$cluster, respectively, shows the significant difference in clustering caused by voltage switching (Fig. 14b). The acetate signal is more than 100 times greater than the first cluster, while iodide is only 5 times greater than the corresponding $\left[\mathrm{I} \cdot \mathrm{H}_{2} \mathrm{O}\right]^{-}$ cluster; this also shows the time needed to reestablish the cluster distribution inside the IMR, which requires about 3 min to equilibrate at 100 mbar with voltage switching but without IMR pressure control.

A potential problem with switching reagent ions is cross talk - the possibility that residual reagent from the previous mode can act as a reagent ion while operating in the alternative mode. We do not observe any direct evidence of this occurring for two reasons. First, the detection of iodide clusters is nearly impossible with acetate's strong declustering voltage settings, and we are currently focused on iodide clusters $[\mathrm{I}+\mathrm{M}]^{-}$while operating in iodide mode. Iodide mode does produce numerous deprotonated, declustered species that are likely peroxycarboxylic acid-containing species, but the interpretation of this region of the mass spectra remains suspect due to a lack of authentic standards (Mielke et al., 2012). Second, ambient acetate calibration and background data show no obvious difference in variability due to operating in switching mode during the beginning of SOAS compared to operating the instrument in dedicated acetate mode for the latter part of SOAS. While not the focus of this study, detection of acetic acid and hydroiodic acid using iodide CIMS and acetate CIMS, respectively, in a reagent switching setup may suffer a larger cross talk problem because the detected species are the reagent ions in the complementary mode. The use of hourly zeros, or zeros immediately after switching reagents, may counteract these effects but would require investigation.

The hourly calibrations conducted during acetate mode CIMS show consistent agreement between standard addition

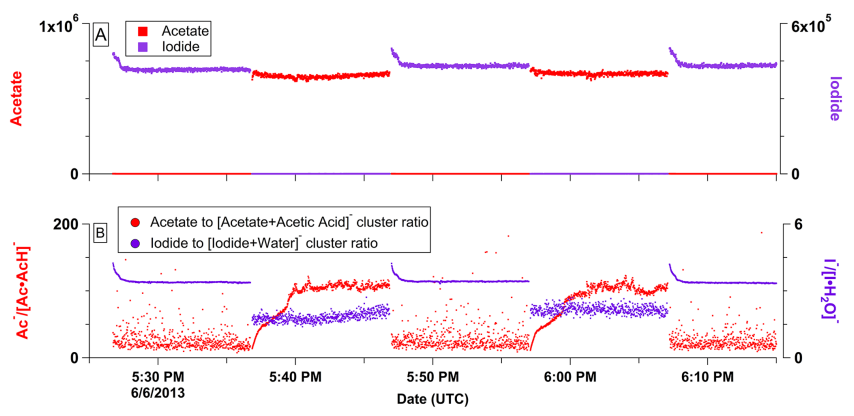

Figure 14. Rapid reagent switching between acetate and iodide with voltage switching. (a) Primary reagent ions; (b) ratio between primary reagent ion and corresponding cluster of interest.

calibrations and external standard calibrations during both switching mode and dedicated acetate mode (Fig. 6). This suggests that switching reagents does not introduce additional matrix effects that alter the sensitivity of formic acid calibrated in zero air relative to ambient air. If reagent ion switching changed the underlying ion-molecule chemistry in the IMR, we would expect to see variability in the background measurements with zero air for acetate mode during switching versus acetate mode in a dedicated acetateonly mode. The backgrounds, however, remain consistently variable between the switching and acetate-only time periods (Fig. 5). Most species exhibit significant changes in background to the same extent over time regardless of whether or not reagent switching is occurring. This is also the case with the LOD and LOQ calculated for formic acid (Fig. 4); both show changes over time, but no abrupt changes occur when dedicated acetate mode is used compared to switching mode. Thus, rapid switching appears to be a robust technique for accessing a larger variety of analyte molecules with a single instrument.

\subsection{The importance of instrument zeros and calibrations}

The hourly determination of instrument zeros during SOAS is essential for accurately quantifying formic acid and tracking the behavior of other gas phase acids using acetate reagents. Figure 15 demonstrates the effect of background subtracting formic acid after applying hourly calibration factors and shows that the absolute value and temporal behavior of formic acid changes depending on the background subtraction method. Applying a single background value to formic acid across the sampling period is insufficient for accurate or precise measurement, and will lead to over- or under-estimation of the instrument background and absolute concentration. The effect of background subtracting by a single value compared to hourly background subtraction can be investigated by correlating the ambient data using the two background approaches. A slope of 1.29, a $y$ intercept of -0.29 , and an $r^{2}=0.79$ suggests that a single background 


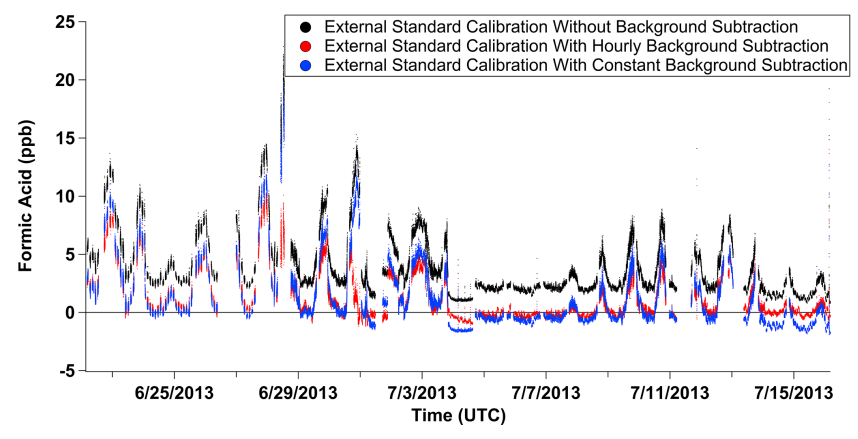

Figure 15. Effect of background subtraction on ambient calculated concentration.

subtraction causes a systematic bias. The direction of the bias will depend on the timing of the single background; in this example, concentrations are overestimated by $\sim 30 \%$. The effect of no background subtraction is also investigated using linear regression which produces the same slope and correlation, but with a much larger $y$ intercept of 2.33, indicative of an overestimate.

Calibrations in zero air and ambient air vary to a lesser extent than the observed variation in background, but remain important (Sect. 4.1). The agreement between the two calibration methods, as described above, is excellent $\left(r^{2}=0.98\right)$, suggesting that no matrix effects, including relative humidity, affect the ionization efficiency of formic acid using acetate as a reagent ion.

This type of systematic instability in sensitivity to formic acid using acetate as a reagent ion is also reported for an HR-TOF-CIMS operating with a micro-orifice volatilization impactor (MOVI) for aerosol sampling (Mohr et al., 2013). Frequent zeros are not presented making it difficult to address whether this instability is actually arising from background fluctuations, a true change in instrument sensitivity to formic acid, or both. Mohr et al. (2013) suggest this instability arises from changes in trailer temperature, which were similar to SOAS operating conditions. Regardless, these two examples of reported instability highlight the importance of hourly calibration and measurement of instrument backgrounds when deploying these instruments in unstable environments typically encountered during field operation.

Unlike acetate, the iodide reagent ion exhibits a humidity dependent sensitivity to formic acid (Lee et al., 2014; Woodward-Massey et al., 2014). The background signal obtained for formic acid in zero air does not represent the true background of the system because of the use of dry zero air. Despite the use of standard additions during iodide acquisition, the quantification of formic acid remains suspect due to our inability to constrain representative background. Iodide backgrounds in dry zero air show similar variability as the acetate backgrounds across the entire mass range (Fig. 5). This provides some evidence that much of the observed variability in the two data sets arises from instrument parameters that are influenced by environmental operating conditions, such as the trailer temperature.

Previous studies using iodide CI have implemented acid scrubbers to remove formic acid (Le Breton et al., 2012). While this technique works for formic acid, it would be unlikely to remove other relevant species such as isomeric isoprene epoxydiols (IEPOX) or isomeric isoprene hydroperoxides (ISOPOOH). Catalytic conversion using a heated catalyst has also been used to generate zero air from ambient air, but incomplete conversion remains a problem as the oxygenated byproducts of incomplete conversion are often detected by CI methods (Lee et al., 2014). The production of zero air and the determination of instrument background remains a challenge that can lead to artificially high LOD and LOQ when compounds of interest are not completely absent.

\subsection{Inlet performance for oxygenated VOC detection}

We limit our analysis of inlet performance to ions that have $\mathrm{S} / \mathrm{N}>3$ and decrease by at least $5 \%$ from ambient during a nitrogen overflow of the inlet (Fig. 13). Most of the species analyzed have residence times between 1 and $2 \mathrm{~s}$, but longer residence times ( $\sim 3.5 \mathrm{~s}$ ) do exist for $\mathrm{Cl}^{-}$and $\mathrm{C}_{8} \mathrm{H}_{11} \mathrm{O}_{4}^{-}$. Recent work characterizing Teflon chambers shows that chemistry dependent wall losses occur (Zhang et al., 2014). Similar surface chemistry is likely occurring inside the PFA tubing of the inlet and contributes to the observed distribution of residence time. Unfortunately, this experiment occurs at 22:45 EST during SOAS, corresponding to a minimum in the number and concentration of species in ambient air. This inherently limits our analysis to a small subset of nighttime species, but does demonstrate that different species behave differently in the inlet.

\subsection{Formic acid measurements during SOAS}

The formic acid time series obtained during the SOAS campaign exhibits very strong diel variation resembling the behavior of nitric acid (Fig. 8). Nitric acid is produced through secondary photochemical reactions, and a strong correlation between nitric acid and formic acid would suggest that formic acid primarily arises from secondary photochemical processing. Detailed analysis of this data set shows that nitric acid and formic acid are well correlated $\left(r^{2}=0.78\right)$, suggesting both may have similar sources and sinks at SOAS (Millet et al., 2015).

This correlation is contrasted by recent airborne (Le Breton et al., 2014) and ground based measurements (Bannan et al., 2014) during the Winter ClearfLo Campaign over the United Kingdom using a quadrupole CIMS implementing the iodide reagent ion for the detection of formic and nitric acid. In that study, airborne measurements of formic acid and nitric acid are less correlated $\left(r^{2}=0.59\right)$, and the ground based measurements show very low correlation $\left(r^{2}=0.14\right)$. This difference between SOAS and the ClearFlo campaign 
suggest a difference in sources, and potentially sinks, between regions dominated by anthropogenic versus biogenic emissions. Direct formic acid emissions may dominate regions with high anthropogenic emissions while secondary sources may dominate regions with primarily biogenic influences (Paulot et al., 2011). In the biogenic-dominated SOAS data set, rapid photochemical sources and rapid sinks are required to explain the diel profile. There is no evidence for such rapid sinks in the ClearFlo data sets, suggesting a less rapid sink of formic acid, potentially due to seasonal or landcover differences.

Ground based gas phase acid measurements during CalNex 2010 in Pasadena, California, with an acetate CIMS showed significant enhancement of formic acid from night to day (Veres et al., 2011). Nitric acid correlates with formic acid $\left(r^{2}=0.59\right)$ and is similar to what is found over the United Kingdom during the winter. Formic acid peaks at noon during the CalNex study, but peak formic acid occurs around 15:00 local time at SOAS. In both cases, formic acid continually decreases overnight.

\subsection{Other acids detected during SOAS}

Numerous ions detected using acetate have high signal-tonoise ratios providing direction for future investigations using HR-TOF-CIMS. Out of the 621 ions fit in the acetate spectra, $198 \mathrm{HR}$ ions fit from 32 to $320 \mathrm{~m} / z$ have $\mathrm{S} / \mathrm{N}>3$ and 57 ions have $\mathrm{S} / \mathrm{N}>10$ during the peak photochemical hour on 28 June of the SOAS study. Formic $\left(\mathrm{CH}_{2} \mathrm{O}_{2}\right)$, acrylic $\left(\mathrm{C}_{3} \mathrm{H}_{4} \mathrm{O}_{2}\right)$, propanoic $\left(\mathrm{C}_{3} \mathrm{H}_{6} \mathrm{O}_{2}\right)$, methacrylic $\left(\mathrm{C}_{4} \mathrm{H}_{6} \mathrm{O}_{2}\right)$, and the sum of pyruvic $\left(\mathrm{C}_{3} \mathrm{H}_{4} \mathrm{O}_{3}\right)$ and butyric $\left(\mathrm{C}_{4} \mathrm{H}_{8} \mathrm{O}_{2}\right)$ acid concentrations are reported during the CalNex study (Veres et al., 2011). These acids all follow the general trend observed for formic acid during that study with strong daytime enhancement relative to nighttime concentrations. Similar behavior for many of the species occurs during SOAS, although authentic calibration for each compound was not conducted (Fig. 9a). The use of a HR-TOF-CIMS allows for the molecular composition of each ion to be determined, and in the case of pyruvic and butyric acid, HR fitting allows for the separation of the isobaric species.

Glycolic $\left(\mathrm{C}_{2} \mathrm{H}_{4} \mathrm{O}_{3}\right)$ acid and lactic acid $\left(\mathrm{C}_{3} \mathrm{H}_{6} \mathrm{O}_{3}\right)$ (possibly the sum of lactic acid and hydroxy-propanoic acid) are detectable species and have the potential for permeation tube based calibration (Veres et al., 2008) (Fig. 9b). Isocyanic acid (HNCO) is of great interest for public health and air quality, and calibration methods exist using a thermal decomposition-diffusion source (Roberts et al., 2010; Wentzell et al., 2013; Woodward-Massey et al., 2014). 2,2Dihydroxy acetic acid $\left(\mathrm{C}_{2} \mathrm{H}_{4} \mathrm{O}_{4}\right)$ exhibits an interesting time series in which ion signal at low concentration drops to zero due to the complete absence of background signal during zero air measurements. This provides one of the few examples where background count rates do not influence the measurement. Numerous other oxidized species exist in the data, and HR analysis provides some insight to these molecules. However, this analysis is complicated by the presence of isobaric isomers. For example, $\mathrm{C}_{4} \mathrm{H}_{4} \mathrm{O}_{3}$ could be a number of different compounds including various oxo-butenoic acids, hydroxy-butynoic acids, or a hydroxy furanone.

Biogenic oxidation products with carboxylic acid functionality behave similarly to formic acid (Fig. 9c). Methacrylic acid epoxide (MAE, $\mathrm{C}_{4} \mathrm{H}_{6} \mathrm{O}_{3}$ ) is detected with high signal-to-noise and is a known oxidation product of isoprene under high $\mathrm{NO}_{x}$ conditions arising from hydroxyl radial oxidation of MPAN (Lin et al., 2013). MAE is highly correlated with formic acid $\left(r^{2}=0.92\right)$. Various examples of terpene related oxidation products also exhibit good signal and temporal variability that is consistent with the smaller acids. Ketopinic acid $\left(\mathrm{C}_{10} \mathrm{H}_{14} \mathrm{O}_{3}\right)$, pinonic acid $\left(\mathrm{C}_{10} \mathrm{H}_{16} \mathrm{O}_{3}\right)$, pinic acid $\left(\mathrm{C}_{9} \mathrm{H}_{14} \mathrm{O}_{4}\right)$, and an unknown compound $\left(\mathrm{C}_{9} \mathrm{H}_{14} \mathrm{O}_{5}\right)$ are presented as examples. Commercially available standards of ketopinic and pinonic acid exist but only in certain isomeric forms.

This discussion leads to two directions of future study. Performing and developing calibrations for as many of these compounds as possible will provide quantitative, speciated data to modelers; it should be acknowledged that knowing the temporal behavior without quantification is also of importance. Even for the simple case of formic acid, current models cannot capture the observed diel cycle observed at SOAS with the known sources and sinks (Millet et al., 2015). Thus, it is questionable how providing a long list of quantified species will aid the current understanding of atmospheric oxidation. Alternatively, placing these CIMS measurements into a frame work for examining bulk gas phase trends needs to be explored and developed. Many frameworks exist for understanding aerosol chemistry, but it is not clear that these frameworks are appropriate for analysis of gas phase CIMS data. The mass defect enhancement plot presented in this paper offers one possible approach, but the interpretation of this space across multiple CIMS methods or locations remains a challenge (Fig. 10a-d).

\subsection{Species detected with iodide}

The mass defect enhancement plot acquired in iodide mode shows the 394 species that change by at least $5 \%$ between a $1 \mathrm{~h}$ average at 06:00 and a $1 \mathrm{~h}$ average at 18:00 on 22 June, highlighting the complexity of the mass spectra obtained by the HR-TOF-CIMS (Fig. 12). Given the limited usefulness of the hourly zero air measurements during iodide mode (Sect. 4.1) we compare the changes in ambient diel data rather than calculating the mass defect enhancement plot from zero air spectra. Six time series of species clustered with iodide are provided to show the temporal variability of species of interest (Fig. 11). These include known isoprene oxidation products isomeric isoprene hydroperoxides (ISOPOOH) and isomeric isoprene epoxydiols (IEPOX), which are detected as a single ion $\left[\mathrm{I} \cdot \mathrm{C}_{5} \mathrm{H}_{10} \mathrm{O}_{3}\right]^{-}$(Paulot et 
al., 2009a). Additional oxidation products following the pattern of $\mathrm{C}_{5} \mathrm{H}_{10} \mathrm{O}_{n}$ also appear in the data and correspond to the successive addition of oxygen, likely proceeding via direct $\mathrm{OH}$ oxidation or by autooxidation (Crounse et al., 2013). Recent study of the photooxidation of levoglucosan using a HR-TOF-CIMS observes similar additions of oxygen to levoglucosan producing a series of oxidation products (Zhao et al., 2014). Isoprene hydroxy nitrate $\left(\mathrm{C}_{5} \mathrm{H}_{9} \mathrm{NO}_{4}\right)$ is observed along with isoprene peroxy nitrate $\left(\mathrm{C}_{5} \mathrm{H}_{9} \mathrm{NO}_{5}\right)$ (Perring et al., 2009; Paulot et al., 2009b). Measurements of isoprene hydroxy nitrate by $\mathrm{CF}_{3} \mathrm{O}^{-}$during the BEARPEX 2009 study exhibit strong variation from night to day as observed at SOAS (Beaver et al., 2012).

\section{Conclusions}

Ambient formic acid measurements in the southeastern United States are presented using a novel configuration of the HR-TOF-CIMS. The average LOD and LOQ for formic acid are 82 and $863 \mathrm{ppt}$, respectively, corresponding to an average sensitivity of $13 \pm 5 \mathrm{~Hz} \mathrm{ppt}^{-1}$ corresponding to an extraction frequency of $17 \mathrm{kHz}$. Instrument backgrounds during SOAS are highly variable, and hourly zeros are essential for quantification. Online switching between acetate and iodide reagent ions does not change the underlying ionization chemistry and shows negligible cross-contamination, thus providing a promising route to measuring a greater number of species in the field with a single mass spectrometer. The low pressure fast flow inlet and the associated calibration source show little hysteresis, have short residence times for most compounds $(<2 \mathrm{~s})$, and generate stable sampling conditions over long periods of time with no maintenance. Frequent (i.e., hourly) zeroing and calibration of the CIMS is essential for accurately quantifying gas phase species in the ambient atmosphere. Overflowing the inlet with high purity zero air works well for determining background signals for acetate CI, but the need to replicate ambient humidity conditions prevents this from being a useful method for determining iodide CI background.

Quantification of a large suite of species remains quite challenging due to the difficulties associated with generating gas phase standards of low volatility, high $\mathrm{O} / \mathrm{C}$ species, and identifying the complex humidity dependence observed with iodide CI. Standards for many of the species either do not exist, or exist in limited forms. Many of the complex species of interest are detected as a single ion, but the ions reaching the detector are an ensemble of isomers that are detected with different sensitivities making analysis complex. Tandem mass spectrometers or ion mobility mass spectrometers coupled to an HR-TOF provide a route to deconvolving these complex spectra. The SRI-HR-TOF-CIMS may be able to deconvolve some of the complex signals consisting of multiple isomeric species because each reagent has different sensitivities to different compounds, with some com- pounds being detected in only one reagent ion. For example, methacrylic and acrylic acid are detected by acetate CIMS, but only methacrylic acid is detected by iodide CIMS.

Bulk analysis of HR CIMS data needs further work, but the mass defect enhancement plotting method outlined here provides one route for eliminating most of the background ions detected on CIMS instruments. This reduces the number of individual species one must sort through, and draws attention to the species most easily detected for a specific experiment.

\section{The Supplement related to this article is available online at doi:10.5194/amt-8-2945-2015-supplement.}

Acknowledgements. We acknowledge the National Science Foundation (AGS 1240611) and the Hermann Frasch Foundation (708-HF12) for funding. We would like to thank Aerodyne Research, Inc and Tofwerk, AG for their support and continual development of the HR-TOF-CIMS. We would also like to acknowledge Trey Murschell for his contribution in running the instrument for part of the SOAS campaign, and Karsten Baumann and Eric Edgerton of Atmospheric Analysis and Research, Inc. for providing nitric acid data.

Edited by: T. F. Hanisco

\section{References}

Aljawhary, D., Lee, A. K. Y., and Abbatt, J. P. D.: High-resolution chemical ionization mass spectrometry (ToF-CIMS): application to study SOA composition and processing, Atmos. Meas. Tech., 6, 3211-3224, doi:10.5194/amt-6-3211-2013, 2013.

Bannan, T. J., Bacak, A., Muller, J. B. A., Booth, A. M., Jones, B., Le Breton, M., Leather, K. E., Ghalaieny, M., Xiao, P., Shallcross, D. E., and Percival, C. J.: Importance of direct anthropogenic emissions of formic acid measured by a chemical ionization mass spectrometer (CIMS) during the Winter ClearfLo Campaign in London, January 2012, Atmos. Environ., 83, 301310, 2014.

Beaver, M. R., Clair, J. M. St., Paulot, F., Spencer, K. M., Crounse, J. D., LaFranchi, B. W., Min, K. E., Pusede, S. E., Wooldridge, P. J., Schade, G. W., Park, C., Cohen, R. C., and Wennberg, P. O.: Importance of biogenic precursors to the budget of organic nitrates: observations of multifunctional organic nitrates by CIMS and TD-LIF during BEARPEX 2009, Atmos. Chem. Phys., 12, 5773-5785, doi:10.5194/acp-12-5773-2012, 2012.

Bertram, T. H., Kimmel, J. R., Crisp, T. A., Ryder, O. S., Yatavelli, R. L. N., Thornton, J. A., Cubison, M. J., Gonin, M., and Worsnop, D. R.: A field-deployable, chemical ionization timeof-flight mass spectrometer, Atmos. Meas. Tech., 4, 1471-1479, doi:10.5194/amt-4-1471-2011, 2011.

Crounse, J. D., McKinney, K. A., Kwan, A. J., and Wennberg, P. O.: Measurement of gas-phase hydroperoxides by chemical ionization mass spectrometry, Anal. Chem., 78, 6726-6732, 2006. 
Crounse, J. D., Nielsen, L. B., Jørgensen, S., Kjaergaard, H. G., and Wennberg, P. O.: Autoxidation of organic compounds in the atmosphere, J. Phys. Chem. Lett., 4, 3513-3520, 2013.

Chhabra, P. S., Lambe, A. T., Canagaratna, M. R., Stark, H., Jayne, J. T., Onasch, T. B., Davidovits, P., Kimmel, J. R., and Worsnop, D. R.: Application of high-resolution time-of-flight chemical ionization mass spectrometry measurements to estimate volatility distributions of a-pinene and naphthalene oxidation products, Atmos. Meas. Tech., 8, 1-18, doi:10.5194/amt-8-1-2015, 2015.

DeCarlo, P. F., Kimmel, J. R., Trimborn, A., Northway, M. J., Jayne, J. T., Aiken, A. C., Gonin, M., Fuhrer, K., Horvath, T., Docherty, K. S., Worsnop, D. R., and Jimenez, J. L.: Field-deployable, high-resolution, time-of-flight aerosol mass spectrometer, Anal. Chem., 78, 8281-8289, 2006.

Ehn, M., Kleist, E., Junninen, H., Petäjä, T., Lönn, G., Schobesberger, S., Dal Maso, M., Trimborn, A., Kulmala, M., Worsnop, D. R., Wahner, A., Wildt, J., and Mentel, Th. F.: Gas phase formation of extremely oxidized pinene reaction products in chamber and ambient air, Atmos. Chem. Phys., 12, 5113-5127, doi:10.5194/acp-12-5113-2012, 2012.

Ehn, M., Thornton, J. A., Kleist, E., Sipilä, M., Junninen, H., Pullinen, I., Springer, M., Rubach, F., Tillman, R., Lee, B., Lopez-Hilfiker, F., Andres, S., Acir, I., Rissanen, M., Jokinen, T., Schobesberger, S., Kangasluoma, J., Kontkanen, J., Nieminen, T., Kurtén, T.,Nielsen, L. B., Jørgensen, S., Kjaergaard, H. G., Canagaratna, M., Dal Maso, M., Berndt, T., Petäjä, T., Wahner, A., Kerminen, V., Kulmala, M., Worsnop, D. R., Wildt, J., and Mentel, T. F.: A large source of low-volatility secondary organic aerosol, Nature, 506, 476-479, 2014.

Ellis, R. A., Murphy, J. G., Pattey, E., van Haarlem, R., O’Brien, J. M., and Herndon, S. C.: Characterizing a Quantum Cascade Tunable Infrared Laser Differential Absorption Spectrometer (QCTILDAS) for measurements of atmospheric ammonia, Atmos. Meas. Tech., 3, 397-406, doi:10.5194/amt-3-397-2010, 2010.

Huey, G. L.: Measurement of trace atmospheric species by chemical ionization mass spectrometry: speciation of reactive nitrogen and future directions, Mass Spectrom. Rev., 26, 166-184, 2007.

Huey, G. L., Hanson, D. R., and Howard, C. J.: Reactions of $\mathrm{SF}_{6}^{-}$ and $\mathrm{I}^{-}$with atmospheric trace gases, J. Phys. Chem., 99, 50015008, 1995.

Jordan, A., Haidacher, S., Hanel, G., Hartungen, E., Herbig, J., Märk, L., Schottkowsky, R., Seehauser, H., Sulzer, P., and Märk, T. D.: An online ultra-high sensitivity proton-transfer-reaction mass-spectrometer combined with a switchable reagent ion capability (PTR+SRI-MS), Int. J. Mass Spectrom., 286, 32-38, 2009.

Junninen, H., Ehn, M., Petäjä, T., Luosujärvi, L., Kotiaho, T., Kostiainen, R., Rohner, U., Gonin, M., Fuhrer, K., Kulmala, M., and Worsnop, D. R.: A high-resolution mass spectrometer to measure atmospheric ion composition, Atmos. Meas. Tech., 3, 10391053, doi:10.5194/amt-3-1039-2010, 2010.

Kercher, J. P., Riedel, T. P., and Thornton, J. A.: Chlorine activation by $\mathrm{N}_{2} \mathrm{O}_{5}$ : simultaneous, in situ detection of $\mathrm{ClNO}_{2}$ and $\mathrm{N}_{2} \mathrm{O}_{5}$ by chemical ionization mass spectrometry, Atmos. Meas. Tech., 2, 193-204, doi:10.5194/amt-2-193-2009, 2009.

Le Breton, M., McGillen, M. R., Muller, J. B. A., Bacak, A., Shallcross, D. E., Xiao, P., Huey, L. G., Tanner, D., Coe, H., and Percival, C. J.: Airborne observations of formic acid using a chemical ionization mass spectrometer, Atmos. Meas. Tech., 5, 30293039, doi:10.5194/amt-5-3029-2012, 2012.
Le Breton, M., Bacak, A., Muller, J. B. A., Xiao, P., Shallcross, B. M. A., Batt, R., Cooke, M. C., Shallcross, D. E., Bauguitte, S. J.-B., and Percival, C. J.: Simultaneous airborne nitric acid and formic acid measurements using a chemical ionization mass spectrometer around the UK: analysis of primary and secondary pathways, Atmos. Environ., 83, 166-175, 2014.

Lee, B. H., Lopez-Hilfiker, F. D., Mohr, C., Kurtén, T., Worsnop, D. R., and Thornton, J. A.: An iodide-adduct high-resolution time-of-flight chemical-ionization mass spectrometer: applications to atmospheric inorganic and organic compounds, Environ. Sci. Technol., 48, 6309-6317, 2014.

Lin, Y., Zhang, H., Pye, H. O. T., Zhang, Z., Marth, W. J., Park, S., Arashiro, M., Cui, T., Budisulistiorini, S. H., Sexton, K. G., Vizuete, W., Xie, Y., Luecken, D. J., Piletic, I. R., Edney, E. O., Bartolotti, L. J., Gold, A., and Surratt, J. D.: Epoxide as a precursor to secondary organic aerosol formation from isoprene photooxidation in the presence of nitrogen oxides, Proc. Natl. Aca. Sci., 110, 6718-6723, 2013.

Mielke, L. H. and Osthoff, H. D.: On quantitative measurements of peroxycarboxylic nitric anhydride mixing ratios by thermal dissociation chemical ionization mass spectrometry, Int. J. Mass Spectrom., 310, 1-9, 2012.

Mielke, L. H., Furgeson, A., and Osthoff, H. D.: Observation of $\mathrm{ClNO}_{2}$ in a mid-continental urban environment, Environ. Sci. Technol., 45, 8889-8896, 2011.

Millet, D. B., Baasandorj, M., Farmer, D. K., Thornton, J. A., Baumann, K., Brophy, P., Chaliyakunnel, S., de Gouw, J. A., Graus, M., Hu, L., Koss, A., Lee, B. H., Lopez-Hilfiker, F. D., Neuman, J. A., Paulot, F., Peischl, J., Pollack, I. B., Ryerson, T. B., Warneke, C., Williams, B. J., and Xu, J.: A large and ubiquitous source of atmospheric formic acid, Atmos. Chem. Phys., 15, 6283-6304, doi:10.5194/acp-15-6283-2015, 2015.

Mohr, C., Lopez-Hilfiker, F. D., Zotter, P., Prévôt, A. S. H., Xu, L., Ng, N. L., Herndon, S. C., Williams, L. R., Franklin, J. P., Zahniser, M. S., Worsnop, D. R., Knighton, W. B., Aiken, A. C., Gorkowski, K. J., Dubey, M. K., Allan, J. D., and Thornton, J. A.: Contribution of nitrated phenols to wood burning brown carbon light absorption in Detling, United Kingdom during winter time, Environ. Sci. Technol., 47, 6316-6324, 2013.

Nozière, B., Kalberer, M., Claeys, M., Allan, J., D’Anna, B., Decesari, S., Finessi, E., Glasius, M., Grgić, I., Hamilton, J. F., Hoffmann, T., Iinuma, Y., Jaoui, M., Kahnt, A., Kampf, C. J., Kourtchev, I., Maenhaut, W., Marsden, N., Saarikoski, S., Schnelle-Kreis, J., Surratt, J., Szidat, S., Szmigielski, R., and Wisthaler, S.: The molecular identification of organic compounds in the atmosphere: state of the art and challenges, Chem. Rev., 115, 3919-3983, doi:10.1021/cr5003485, 2015.

Paulot, F., Crounse, J. D., Kjaergaard, H. G., Kürten, A., St. Clair, J. M., Seinfeld, J. H., and Wennberg, P. O.: Unexpected epoxide formation in the gas-phase photooxidation of isoprene, Science, 325, 730-733, 2009a.

Paulot, F., Crounse, J. D., Kjaergaard, H. G., Kroll, J. H., Seinfeld, J. H., and Wennberg, P. O.: Isoprene photooxidation: new insights into the production of acids and organic nitrates, Atmos. Chem. Phys., 9, 1479-1501, doi:10.5194/acp-9-1479-2009, 2009 b.

Paulot, F., Wunch, D., Crounse, J. D., Toon, G. C., Millet, D. B., DeCarlo, P. F., Vigouroux, C., Deutscher, N. M., González Abad, G., Notholt, J., Warneke, T., Hannigan, J. W., Warneke, C., de Gouw, J. A., Dunlea, E. J., De Mazière, M., Griffith, D. 
W. T., Bernath, P., Jimenez, J. L., and Wennberg, P. O.: Importance of secondary sources in the atmospheric budgets of formic and acetic acids, Atmos. Chem. Phys., 11, 1989-2013, doi:10.5194/acp-11-1989-2011, 2011.

Perring, A. E., Wisthaler, A., Graus, M., Wooldridge, P. J., Lockwood, A. L., Mielke, L. H., Shepson, P. B., Hansel, A., and Cohen, R. C.: A product study of the isoprene+NO3 reaction, Atmos. Chem. Phys., 9, 4945-4956, doi:10.5194/acp-9-4945-2009, 2009.

Roberts, J. M., Veres, P., Warneke, C., Neuman, J. A., Washenfelder, R. A., Brown, S. S., Baasandorj, M., Burkholder, J. B., Burling, I. R., Johnson, T. J., Yokelson, R. J., and de Gouw, J.: Measurement of HONO, HNCO, and other inorganic acids by negative-ion proton-transfer chemical-ionization mass spectrometry (NI-PT-CIMS): application to biomass burning emissions, Atmos. Meas. Tech., 3, 981-990, doi:10.5194/amt-3-981-2010, 2010.

Smith, D. and Španěl, P.: Selected ion flow tube mass spectrometry (SIFT-MS) for on-line trace gas analysis, Mass Spectrom. Rev., 24, 661-700, 2005.

Slusher, D. L., Huey, L. G., Tanner, D. J, Flocke, F. M., and Roberts, J. M.: A thermal dissociation-chemical ionization mass spectrometry (TD-CIMS) technique for the simultaneous measurement of peroxyacyl nitrates and dinitrogen pentoxide, J. Geophys. Res., 109, D19315, doi:10.1029/2004JD004670, 2004.

Veres, P., Roberts, J. M., Warneke, C., Welsh-Bon, D., Zahniser, M., Herndon, S., Fall, R., and de Gouw, J.: Development of negativeion proton-transfer chemical-ionization mass spectrometry (NIPT-CIMS) for the measurement of gas-phase organic acids in the atmosphere, Int. J. Mass Spectrom., 274, 48-55, 2008.
Veres, P., Roberts, J. M., Cochran, A. K., Gilman, J. B., Kuster, W. C., Holloway, J. S., Graus, M., Flynn, J., Lefer, B., Warneke, C., and de Gouw, J.: Evidence of rapid production of organic acids in an urban air mass, Geophys. Res. Lett., 38, L17807, doi:10.1029/2011GL048420, 2011.

Wentzell, J. J. B., Liggio, J., Li, S., Vlasenko, A., Staebler, R., Lu, Gang, Poitras, M., Chan, T., and Brook, J. R.: Measurements of gas phase acids in diesel exhaust: a relevant source of HNCO?, Environ. Sci. Technol., 47, 7663-7671, 2013.

Woodward-Massey, R., Taha, Y. M., Moussa, S. G., Osthoff, H. D.: Comparison of negative-ion proton-transfer with iodide ion chemical ionization mass spectrometry for quantification of isocyanic acid in ambient air, Atmos. Environ., 92, 693-703, 2014.

Yatavelli, R. L. N., Lopez-Hilfiker, F. Wargo, J. D., Kimmel, J. R., Cubison, M. J., Bertram, T. H., Jimenez, J. L., Gonin, M., Worsnop, D. R., and Thorton, J. A.: A chemical ionization highresolution time-of-flight mass spectrometer coupled to a micro orifice volatilization impactor (MOVI-HRToF-CIMS) for analysis of gas and particle-phase organic species, Aerosol Sci. Tech., 46 1313-1327, 2012.

Zhang, X., Cappa, C. D., Jathar, S. H., McVay, R. C., Ensberg, J. J., Kleeman, M. J., amd Seinfeld, J. H.: Influence of vapor wall loss in laboratory chambers on yields of secondary organic aerosol, Proc. Natl. Acad. Sci., 11, 5802-5807, 2014.

Zhao, R., Mungall, E. L., Lee, A. K. Y., Aljawhary, D., and Abbatt, J. P. D.: Aqueous-phase photooxidation of levoglucosan a mechanistic study using aerosol time-of-flight chemical ionization mass spectrometry (Aerosol ToF-CIMS), Atmos. Chem. Phys., 14, 9695-9706, doi:10.5194/acp-14-9695-2014, 2014. 